- Behavioral Health: Putting Evidence into Practice, presented by Lauren Oshman MD, MPH, Lindsay Fazio, PhD; Ravi Grivois-Shah, MD; Manisha Sharma, MD; and Santina Wheat, MD, MPH, AAHIVS

The new educational series is one of several CME products on behavioral and mental health produced by the Academy. The AAFP is also a member of the recently formed Behavioral Health Integration Collaborative, a group of 8 physician organizations working together to incorporate behavioral and mental health into overall health care and increase patient access to behavioral health services in the primary care setting. AAFP News

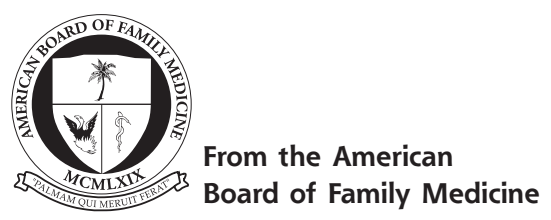

Ann Fam Med 2021;19:282-284. https://doi.org/10.1370/afm.2705.

\section{LEARNING FROM COVID-19: SYSTEM BLINDNESS TO PRIMARY CARE}

It has become common to observe that the COVID-19 pandemic has unmasked - again ${ }^{1}$ - the inequities in health care that Black, Latino, and poor patients face in access to and delivery of care. ${ }^{2,3}$ Less commonly observed is the blindness to the potential for primary care to have played a major role in response to the pandemic. We believe that this blindness has cost lives and increased suffering in communities across the country.

Primary care is the largest health care delivery platform in the country. Personal physicians ${ }^{4}$ include family physicians, general internists, and pediatricians, with family physicians representing the largest and most widely distributed tribe of personal physicians. ${ }^{5}$ Primary care practices also include the nurse practitioners, physician assistants, and other professionals who choose to practice in primary care. Together, in a typical year in the United States, they provide over $4,000,000$ office visits annually, $46 \%$ of vaccinations, ${ }^{6,7}$ and countless hours in care coordination, telephone, and other non-direct care. Additionally, tens of thousands of family physicians care for patients across the continuum of care, from hospital medical wards, to labor and delivery suites, to nursing homes and other community sites. This is what we do.

Then the pandemic hit. In a period of merely 2 weeks last March, much of primary care in the United States became virtual. This happened as hospitals shut down elective procedures and patients became fearful of coming to the office. In response to the needs of patients and communities, many family physicians developed fundamentally new approaches to care, learning how to triage office visits, develop telehealth infrastructure and protocols, protect staff and patients, while balancing personal and professional commitments and constantly adapting to rapidly changing local conditions. Family physicians and their teams often did this often without personal protective equipment.

Faced with a shortage of PPE and large increases in demand, decisions made by the CDC and states often sent PPE exclusively to emergency departments and hospitals. Weekly surveys from the Green Center document this clearly and painfully. While not a random sample, they nevertheless demonstrated that $51 \%$ of a national sample of 755 primary care practices reported major challenges to protecting themselves in March of 2020; by November, access was improved but still $32 \%$ had major problems with PPE. ${ }^{8}$ Funneling PPE to hospitals ignored the reality that the vast majority of health care visits in the country are to primary care, even after substantial virtualization. For patients who have a relationship with a personal physician, the need for advice and care increases in a time of fear and uncertainty.

As a result, and predictably, family physicians' deaths due to COVID-19 have far outpaced other specialties. In the initial phase of the epidemic, almost 4 times as many family physicians died of COVID-19 than emergency physicians and critical care physicians combined. ${ }^{9}$ While these data do not have denominators and must be interpreted carefully, they represent evidence of a systematic inequity in the organization of health care and distribution of lifesaving resources.

There has been a similar blindness to the role of primary care offices in providing diagnostic services and giving COVID-19 vaccinations. Most family physician offices provide a broad array of point-of-care tests for infectious diseases such as strep throat, influenza, and sexually transmitted infections. These services are offered in the context of a relationship with a trusted personal physician, who can counsel on the implications of the tests. Of course, new diagnostic technology for COVID-19 had to be developed, approved, and spread, and clinicians have had to learn to use and interpret these new tests initially without knowing the natural history of coronavirus shedding. But what emerged, and is still very common, is a "diagnostic center" approach in which patients often use drive-through community ("tent clinics") or pharmacy-based testing that are largely removed from personal interpretation, patient education, and implications. The lesson for patients? For the most feared disease of this generation, don't go to your family physician for diagnosis. You are 
largely on your own to interpret the results, and cope with the diagnosis, without help from someone you know and trust, unless you call your family physician.

A similar pattern emerged with vaccination. In non-pandemic times, almost one-half of the vaccinations in the United States are administered in primary care settings. ${ }^{6,7}$ But with the pandemic, virtually none have been. The major strategy used nationally was to emphasize hospitals and pharmacy chains. The reasons for this are numerous and range from the scale necessary to vaccinate thousands of people a day to the need for ultra-cold refrigerators that were perceived to be difficult to find outside of urban centers. The message to patients? To prevent the most feared disease of the century, don't go to primary care. In fact, including primary care alongside community pharmacies and hospital vaccination clinics can be complementary, as suggested by the success of West Virginia, the nation's leading state for COVID-19 vaccine administration, ${ }^{10}$ as well as the United Kingdom. ${ }^{11}$ Similarly, as we worry about vaccine hesitancy, leaving primary care largely out of vaccinations squanders the social capital of the trust patients have in their family physicians and their offices. Who better to address vaccine hesitancy than family physicians working individually with their patients?

So, in the end, our clinical response to the community face of the pandemic, from diagnosis, to vaccination, to personal safety of physicians and their staff, has largely excluded primary care. In a way, this was not surprising. Although the US Pandemic plan had been updated in 2017, primary care had no defined role. ${ }^{12}$

Why? We do not believe, nor suggest, that it was intentional. The nation was coping with a once-ina-century event which spread rapidly, without time for preparation. There has been much to learn about all aspects of COVID-19 care, and all of us must be humble about learning these lessons. Yet, the fact that aligning with family medicine and primary care was not considered in the pandemic response is a clear sign of the blindness to primary care. It is indicative of a habit of mind so entrenched that it becomes a barrier to change. "Not thinking" of the largest health care platform in the country-the one that provides the most care for patients across all communities in the country - is nothing more than a bias—a bias toward hospitals, toward corporatization of medicine-and away from patients, communities, and their needs. The problem is longstanding, the result of a fee-for-service system that starves primary care, and rewards hospitals for being full and training subspecialists.

The disaster is in plain sight, for those with eyes to see. So are the solutions. Hope comes in this May's National Academies of Science, Engineering, and
Medicine Consensus Report on the Implementation of High Value Primary Care. It follows up the December declaration of the Boards and Specialty Societies, ${ }^{13}$ representing over 400,000 physicians, calling for a new paradigm of primary care with urgent payment and regulatory reform and calls for change in the GME system to make it more responsive to the needs of society. ${ }^{14}$ All bring clarity about the need for robust primary care, for grounding our system of graduate medical education in the needs of the public, and for a governmental focus on primary care as a public good.

Warren P. Newton, MD, MPH (wnewton@theabfm.org), American Board of Family Medicine, Department of Family Medicine, University of North Carolina, Elizabeth Baxley, MD, American Board of Family Medicine, Michael Magill,

MD, American Board of Family Medicine, Department of Family and Preventive Medicine, University of Utab

\section{References}

1. Institute of Medicine. Unequal Treatment: Confronting Racial and Ethnic Disparities in Health Care. Institute of Medicine; 2003.

2. Evans MK. Covid's color line - infectious disease, inequity, and racial justice. N Engl J Med. 2020;383(5):408-410.

3. Price-Haywood EG, Burton J, Fort D, Seoane L. Hospitalization and mortality among black patients and white patients with Covid-19. N Engl J Med. 2020;382(26):2534-2543.

4. Fox TF. The personal doctor and his relation to the hospital: observations and reflections on some American experiments in general practice by groups. Lancet. 1960;1(7127):743-760.

5. Willis J, Antonio B, Bazemore A, Jetty A, Petterson S. The State of Primary Care in the United States: A Chartbook of Facts and Statistics. Robert Graham Center; 2021.

6. Wilkinson E, Jetty A, Petterson S, Jabbapour Y, Westfall JM. Primary care's historic role in vaccination and potential role in COVID-19 immunization programs [published online ahead of print Mar 11, 2021]. Ann Fam Med. https://www.annfammed.org/content/ early/2021/03/10/afm.2679

7. National Center for Health Statistics. National ambulatory medical care survey: 2016 national summary tables. Accessed Mar 29, 2020. https://ww w.cdc.gov/nchs/data/ahcd/namcs_summary/2016_ namcs_web_tables.pdf

8. Larry Green Center. COVID-19 survey of primary care clinicians and patients/ March 13-16, 2020 survey. Accessed Apr 14, 2021. https:// static1.squarespace.com/static/5d7ff8184cf0e01e4566cb02/t/5e861 fc4f218f93aefa2eb7a/1585848260602/C19+Series +1+PC+Survey+ COVID19+Mar+13-16+Summary.pdf

9. Gouda D, Singh PM, Gouda P, Goudra B. An overview of health care worker reported deaths during the COVID-19 pandemic. J Am Board Fam Med. 2021;34(Suppl):S244-S246.

10. Popperl S, King N, Weiner L. West Virginia's vaccination rate ranks among highest in world. Transcript. Morning Edition. National Public Radio. Feb 22, 2021. Accessed Apr 14, 2021. https://www. npr.org/sections/coronavirus-live-updates/2021/02/22/968829227/ west-virginias-vaccination-rate-ranks-among-highest-in-world

11. The Visual and Data Journalism Team. Covid vaccine: how many people in the UK have been vaccinated so far? BBC News. 2021. Accessed Apr 14, 2021. https://www.bbc.com/news/ health-55274833

12. US Department of Health and Human Services. Pandemic influenza plan 2017 update. Published Dec 2017. https://www.cdc.gov/flu/ pandemic-resources/pdf/pan-flu-report-2017v2.pdf 
13. Unified Vision, Unified Voice: Primary Care Speaks As One. Accessed Apr 15, 2021. https://www.newprimarycareparadigm.org/

14. Newton WP, Mitchell KB, Magill MK. The future of family medicine residency education: the specialty has spoken. Ann Fam Med. 2021; 19(2):185-187. 10.1370/afm.2677

\section{STFM LAUNCHES NEW PHASE OF INITIATIVE TO ADDRESS SHORTAGE OF COMMUNITY PRECEPTORS}

US MD-granting school enrollment grew 33\% between 2002-2003 and 2019-2020. Enrollment at DO-granting schools grew even faster, increasing the need for already scarce clinical training sites for students. ${ }^{1-2}$ According to a 2019 Association of American Medical Colleges survey, $84 \%$ of deans at MD-granting schools are concerned about the number of clinical training sites and $86 \%$ are concerned about the supply of qualified primary care preceptors. ${ }^{1}$

The struggle to obtain and retain high-quality clinical training sites is not new. Since late 2015, The Society of Teachers of Family Medicine (STFM) has been leading an interdisciplinary, interprofessional initiative to decrease the percentage of primary care clerkship directors who report difficulty finding clinical preceptor sites and increase the percentage of students completing clerkships at high-functioning sites.

Although the initiative has celebrated many successes, the increasing competition for clinical training sites, changes in difficulty replacing retired physician volunteers, and "changes in health system alignment impacting student placements" ${ }^{\prime \prime}$ means the need for innovative solutions is ongoing.

STFM has launched a new phase of the Preceptor Expansion Initiative, with broad dissemination of results and resources from Phase One. A key part of this new phase is Promoting Precepting - an AAFP Chapter Engagement Project. This includes:

- A presentation - New Ideas for Tackling the Preceptor Shortage in Your State - for chapter staff and leaders at the AAFP's Chapter Leadership Forum

- A virtual meeting for chapter executives from states that have tax incentives for preceptors to see if the incentives are making an impact

- A virtual panel presentation with and for chapter staff and leaders: The Preceptor Shortage: What's Worked in our State
- Precepting presentations for chapters for their virtual and in-person annual meetings

- Exhibits promoting precepting at chapter meetings

- A series of 1-page tips for chapters to share with preceptors in their publications and/or on their websites. These include:

- Incentives for precepting

- Precepting telemedicine visits

- Student documentation in the EHR

- Giving feedback

- Print and social media ads for chapter publications

Resources and more information is available at https://stfm.org/PreceptingResourcesForChapters.

\section{Update on Phase One}

The Preceptor Expansion Initiative launched in August 2016 with a Summit to identify the most significant reasons for the shortage of community preceptors and to shape the priorities, leadership, and investments needed to ensure the ongoing education of the primary care workforce.

The outcome of the Summit was an action plan that has been implemented over the past several years. Key successes include:

- A change in CMS documentation guidelines to allow students to document in the EMR without redocumentation by the preceptor

- Clerkship onboarding modules for students on how to write a high-quality note in the EMR, how to perform medication reconciliation, and motivational interviewing - A student onboarding passport that is shared with preceptors prior to rotations. It includes demographic information, personal learning objectives, a list of completed rotations, a list of procedural training, and verification of completion of online modules

- A guideline for program administrators or clinical coordinators to assist with community faculty appointments

- Awards for preceptors and precepting practices

- An ABFM Performance Improvement Activity where preceptors meet performance improvement requirements for continuing certification by precepting learners and implementing projects to improve their teaching skills

A project to pilot the resources was completed in December of 2020 and results are pending publication. The resources are available at https://stfm.org/ PreceptorExpansion.

The Preceptor Expansion Initiative is funded by the Society of Teachers of Family Medicine, the American Board of Family Medicine Foundation, and the Physician Assistant Education Association.

Mary Theobald, MBA, Chief of Strategy and Innovation, STFM 